\title{
Maturation of Oxycodone Pharmacokinetics in Neonates and Infants : a Population Pharmacokinetic Model of Three Clinical Trials
}

\section{Valitalo, Pyry}

2017-05

Valitalo , P , Kokki , M , Ranta , V-P , Olkkola , K T , Hooker , A C \& Kokki , H 2017 , '

Maturation of Oxycodone Pharmacokinetics in Neonates and Infants : a Population

Pharmacokinetic Model of Three Clinical Trials ' , Pharmaceutical Research , vol. 34 , no. 5 , pp. 1125-1133 . https://doi.org/10.1007/s11095-017-2122-6

http://hdl.handle.net/10138/234743

https://doi.org/10.1007/s11095-017-2122-6

unspecified

publishedVersion

Downloaded from Helda, University of Helsinki institutional repository.

This is an electronic reprint of the original article.

This reprint may differ from the original in pagination and typographic detail.

Please cite the original version. 


\title{
Maturation of Oxycodone Pharmacokinetics in Neonates and Infants: a Population Pharmacokinetic Model of Three Clinical Trials
}

\author{
Pyry Välitalo' - Merja Kokki ${ }^{2,3}$ - Veli-Pekka Ranta ${ }^{4}$ - Klaus T. Olkkola ${ }^{5}$ - Andrew C. Hooker ${ }^{6}$. \\ Hannu Kokki 2,3
}

Received: 9 December 2016 / Accepted: 9 February 2017 / Published online: 15 February 2017

(C) Springer Science+Business Media New York 2017

\begin{abstract}
Purpose The aim of the current population pharmacokinetic study was to quantify oxycodone pharmacokinetics in children ranging from preterm neonates to children up to 7 years of age.

Methods Data on intravenous or intramuscular oxycodone administration were obtained from three previously published studies $(n=119)$. The median [range] postmenstrual age of the subjects was 299 days [170 days-7.8 years]. A population pharmacokinetic model was built using 781 measurements of oxycodone plasma concentration. The model was used to simulate repeated intravenous oxycodone administration in four representative infants covering the age range from an extremely preterm neonate to 1-year old infant.
\end{abstract}

Results The rapid maturation of oxycodone clearance was best described with combined allometric scaling and

Some of the results have been presented in abstract: Kokki $\mathrm{H}$ Välitalo $\mathrm{P}$, Kokki $M$, Ranta VP, Olkkola KT, Hooker AC. Population pharmacokinetics of oxycodone in neonates and infants. Euroanaesthesia 2016 Congress, 28.-30.5.2016, London, UK.

Electronic supplementary material The online version of this article (doi: | 0. I007/s | 1095-0 17-2 | 22-6) contains supplementary material, which is available to authorized users.

Hannu Kokki

hannu.kokki@uef.fi

Division of Pharmacology, Leiden University, Leiden, The Netherlands

2 Department of Anesthesia and Operative Services, Kuopio University Hospital, PO Box 100, FI-70029 Kuopio, Finland

3 School of Medicine, University of Eastern Finland, Kuopio, Finland

4 School of Pharmacy, University of Eastern Finland, Kuopio, Finland

5 Department of Anesthesiology, Intensive Care and Pain Medicine, University of Helsinki and Helsinki University Hospital, Helsinki, Finland

6 Department of Pharmaceutical Biosciences, Uppsala University, Uppsala, Sweden maturation function. Central and peripheral volumes of distribution were nonlinearly related to bodyweight. The simulations on repeated intravenous administration in virtual patients indicated that oxycodone plasma concentration can be kept between 10 and $50 \mathrm{ng} / \mathrm{ml}$ with a high probability when the maintenance dose is calculated using the typical clearance and the dose interval is $4 \mathrm{~h}$.

Conclusions Oxycodone clearance matures rapidly after birth, and between-subject variability is pronounced in neonates. The pharmacokinetic model developed may be used to evaluate different multiple dosing regimens, but the safety of repeated doses should be ensured.

KEY WORDS analgesic, opioid · infant, extremely premature $\cdot$ oxycodone $\cdot$ pain $\cdot$ pharmacokinetics

$\begin{array}{ll}\text { ABBREVIATIONS } \\ \text { BDE } & \text { Body weight dependent exponent } \\ \text { BSV } & \text { Between-subject variability } \\ \text { CYP } & \text { Cytochrome P450 enzyme } \\ \text { GA } & \text { Gestational age } \\ \text { LLOQ } & \text { Lower limit of quantification } \\ \text { NPDE } & \text { Normalized prediction distribution errors } \\ \text { OFV } & \text { Objective function value } \\ \text { PMA } & \text { Postmenstrual age } \\ \text { PNA } & \text { Postnatal age } \\ \text { PTA } & \text { Probability of target attainment. } \\ \text { TVCL } & \text { Typical clearance } \\ \text { WT } & \text { Body weight }\end{array}$

\section{INTRODUCTION}

Oxycodone is a pure semisynthetic opioid agonist that is commonly used in adults and in the elderly for the treatment of moderate and severe pain, and it is increasingly 
used also in children (1-3). A population pharmacokinetic model of oxycodone has been built for infants and children over 6 months of age, and a fixed weight-based dose has been suggested (4).

The maturation of oxycodone pharmacokinetics is poorly understood in infants less than 6 months of age, since only two studies have been performed. In the first published study of this age group $(n=22)$ no clear trend in the maturation was observed because of marked between-subject variability (BSV) (5). In a recent study $(n=76$ including 64 infants under 6 months) of oxycodone and its metabolites in plasma and urine, a clear trend in the maturation of oxycodone clearance was found. This data suggested that extrarenal (hepatic) clearance increases rapidly during the first months after birth whereas renal clearance remains fairly low and constant (6). In addition, the plasma concentrations of active metabolites, oxymorphone and noroxymorphone, are very low and they are not expected to contribute to the central opioid effects based on the corresponding studies in older children and in adults (7-9).

In the current study, a population pharmacokinetic model of plasma oxycodone was built to describe the maturation of oxycodone pharmacokinetics in infants and children including preterm neonates. The data originated from the two studies mentioned above $(5,6)$ and a third study of oxycodone pharmacokinetics of oxycodone in infants and children over sixth months of age after intravenous $(n=9)$ and intramuscular ( $n=10)$ administration (10). The obtained model was used to simulate oxycodone plasma concentration after repeated intravenous dosing for different age groups to provide preliminary dosing recommendations for further studies and clinical work in small children.

\section{METHODS}

\section{Data}

Data were obtained from three studies $(5,6,10)$. First, data on intravenous oxycodone administration in infants were used from a recent, optimally designed study (Study 1) (6). Most subjects in this study received a single dose of oxycodone. If the patient required hospital care for over 14 days or a readmission the approved study plan allowed studying oxycodone pharmacokinetics for two or three times. Oxycodone was given to 79 infants, one infant received oxycodone three times and six infants twice, and therefore, the total number of dosing events was 87. After the exclusions (see 6), the total number of infants, dosing events and oxycodone plasma concentrations from Study 1 for the population pharmacokinetic modeling were 76, 81 and 397, respectively.

Additionally, earlier published data from two trials were used. The second dataset (Study 2) featured a total of 40 children aged between 6 months and 7 years, receiving a single dose of oxycodone intravenously, intramuscularly, orally (via a gastric tube) or buccally (10). From those data, 19 subjects receiving oxycodone intravenously $(n=9)$ or intramuscularly $(n=10)$ were used. Data from oral and buccal administration were excluded since BSV was significant for these routes. The third dataset (Study 3) contained data for a single intravenous oxycodone dose from a total of 24 neonates and infants aged less than 6 months (5). The original publication presented data only for 22 children since data for one infant were too sparse for noncompartmental analysis used in that study and another infant was aged over 6 months.

In all studies the dose was $0.1 \mathrm{mg} / \mathrm{kg}$ oxycodone hydrochloride trihydrate that corresponds to $0.087 \mathrm{mg} / \mathrm{kg}$ oxycodone hydrochloride and $0.078 \mathrm{mg} / \mathrm{kg}$ oxycodone base, respectively. The studies are described in detail in the original publications $(5,6,10)$.

\section{Analytical Methods}

The oxycodone plasma concentrations are presented as free base. In Study 1 oxycodone plasma concentration was quantified using liquid chromatography-mass spectrometry with a lower limit of quantification (LLOQ) of $0.2 \mathrm{ng} / \mathrm{ml}$ (6). The samples from Study 2 were analyzed using gas chromatography with mass spectrometric detection with a LLOQ of $1 \mathrm{ng} / \mathrm{ml}$ (10). Samples from Study 3 were analyzed with gas chromatography with a LLOQ of $2 \mathrm{ng} / \mathrm{ml}(5)$.

\section{Population Pharmacokinetic Analysis}

\section{General Description}

Data were modeled with NONMEM version 7.3 (11). R version 3.3.1 was used for data management and visualization (12). The Perl-speaks-NONMEM software package was used for run control (13). For comparisons between two nested models, Likelihood Ratio Test was applied. This test consists of comparing differences in Objective Function Value (OFV) between nested models. The difference in OFV are asymptotically chi-square distributed with the degrees of freedom equaling the differences in number of parameters. For example, an OFV difference of 6.63 with one extra parameter corresponds to a $p$-value of 0.01 . For comparisons between two non-nested models, Akaike Information Criterion was used. Furthermore, the choice between models was influenced by the standard errors of parameter estimates, the presence or lack of trends in residuals versus time, the presence or lack of trends in random effects versus covariates, and the clinical interpretability of the model.

Between-subject variability was described with lognormal distributions as shown in Eq. 1: 
$\theta_{\mathrm{i}}=\theta^{*} \exp \left(\eta_{\mathrm{i}}\right)$

where $\eta_{\mathrm{i}}$ is distributed with a mean of zero and a standard deviation of $\operatorname{sd}\left(\eta_{\mathrm{i}}\right)$, which could be dependent on multiple parameters.

Missing data were omitted from the analysis (M1 method) (14) because for one of the studies (5), it was not always known whether the missing data were caused by early termination of sampling or by concentrations being below LLOQ. For residual variability, a combined additive and proportional error (Eq. 2) was initially used, and residual error elements with relative standard error less than 50\% were retained in the model. Separate residual errors were estimated for each study.

$\mathrm{y}_{\mathrm{ij}}=\operatorname{ipred}_{\mathrm{ij}} *\left(\mid+\varepsilon_{\text {prop }}\right)+\varepsilon_{\mathrm{add}}$

where $\varepsilon$ are distributed with a mean of zero and a standard deviation of $\sigma$.

\section{Covariate Model Development}

Several models have been proposed to characterize drug clearance maturation. Two of these approaches were tested, namely body weight dependent exponent (BDE) and maturation function based on postmenstrual age (PMA).

The BDE model features the prediction of typical clearance (TVCL) by body weight (WT) raised to an exponent that is itself a function of WT (Eqs. 3 and 4). Versions of this function include $\mathrm{E}_{\max }$-type function (Eq. 5) (15) and exponential function (Eq. 6) (16).

$\mathrm{TVCL}=\theta_{\mathrm{CL}} *\left(\mathrm{WT} / \mathrm{WT}_{\mathrm{ref}}\right)^{\mathrm{BDE}}$

$\mathrm{BDE}=\mathrm{f}(\mathrm{WT}, \theta)$

$\mathrm{f}(\mathrm{WT}, \theta)=\theta_{1}-\theta_{2} * \mathrm{WT}^{\theta 3} /\left(\theta_{4}{ }^{\theta 3}+\mathrm{WT}^{\theta 3}\right)$

$\mathrm{f}(\mathrm{WT}, \theta)=\theta_{1} * \exp \left(\mathrm{WT} * \theta_{2}\right)$

The PMA-based maturation function is typically combined with scaling by WT with an exponent that is either estimated or fixed to 0.75 (Eq. 7) (17).

$$
\begin{array}{rl}
\text { TVCL }=\theta_{\mathrm{CL}} & *\left(\mathrm{WT} / \mathrm{WT}_{\mathrm{ref}}\right)^{\theta \exp } \\
& * \mathrm{PMA}^{\mathrm{HILL}} /\left(\theta_{\mathrm{PMA} 50}{ }^{\mathrm{HILL}}+\mathrm{PMA}^{\mathrm{HILL}}\right)
\end{array}
$$

The assumption in both of these models is that some maturation of clearance pathways occurs in utero. Due to this maturation, newborns already have some drug elimination capacity at the moment of birth. The BDE model aims to scale the clearance by WT, with an assumption that the exponent itself also varies as a function of WT $(15,16)$.

As a null hypothesis, the volume of distribution was assumed to scale linearly as a function of WT. This assumption was challenged by estimating an allometric exponent for the relationship between volume of distribution and WT (Eq. 8).

$\mathrm{V}=\theta_{\mathrm{V}} *(\mathrm{WT} / 4)^{\theta \exp }$

where $\theta_{\mathrm{V}}$ is the volume of distribution for a typical infant of $4 \mathrm{~kg}$ and $\theta_{\exp }$ is the exponent for the relationship between volume of distribution and WT. A maturation function for volume of distribution was also tested (17) (Eq. 9).

$\mathrm{V}=\theta_{\mathrm{V}}(\mathrm{WT} / 4) *\left(I+\theta_{1}\right) * \exp \left(-\theta_{2} *(\mathrm{WT}-0.4)\right)$

The equation is standardized so that the value of $\theta 1$ is estimated for the lowest observed bodyweight $(0.4 \mathrm{~kg})$ within Study 1 before patient exclusions.

Since BSV of clearance seemed in preliminary models to be higher in neonates than in older children, the standard deviation of clearance variability was modeled as a function of postnatal age (PNA) (Eq. 10).

$\operatorname{sd}(\eta \mathrm{CL}, \mathrm{i})=\mathrm{BSV}_{\text {base }}+\mathrm{BSV}_{\text {add }} * \exp \left(-\mathrm{PNA}^{*} \mathrm{BSV}_{\exp }\right)$

where $\mathrm{BSV}_{\text {base }}$ is the baseline value of $\mathrm{BSV}, \mathrm{BSV}_{\text {add }}$ is the additional BSV at the PNA age of 0 days and $\mathrm{BSV}_{\exp }$ is the exponent for the rate of decrease of additional BSV.

\section{Model Evaluation}

The final model was evaluated with a bootstrap based on 1000 resampled datasets. Normalized prediction distribution errors (NPDE) were calculated based on 1000 simulations (18). Agreement between observations and model predictions was visually compared. Plots of the random effects of clearance were plotted against covariates, for both model without covariates and the final model with covariates.

\section{Representative Dosing Simulations for Neonates and Infants}

The population pharmacokinetic model was used to simulate repeated intravenous administration. Monte Carlo simulations in four virtual patients were performed with an initial dose of $0.1 \mathrm{mg} / \mathrm{kg}$ and subsequent maintenance doses of oxycodone hydrochloride trihydrate at i) every hour or ii) every fourth hour to keep the average plasma concentration at the assumed analgesic concentration of $25 \mathrm{ng} / \mathrm{ml}(19,20)$. The maintenance dose was calculated using the typical clearance of the virtual patient and the average target concentration. The goal was to keep the oxycodone plasma concentrations between 10 and $50 \mathrm{ng} / \mathrm{ml}$, and the probability for achieving this target concentration range was calculated.

The simulations were performed for four virtual patients: 1) an extremely preterm neonate with gestational age (GA) of 
182 days, PNA of 5 days, PMA 187 days, and WT of $0.5 \mathrm{~kg}$ (e.g., ligature of the patent ductus arteriosus), 2) a modest/late preterm neonate with GA 245 days, PNA 1 day, PMA 246 days, and WT $2.2 \mathrm{~kg}$ (e.g., herniotomy); 3) a term newborn with GA 280 days, PNA 1 day, PMA 281 days, WT $3.5 \mathrm{~kg}$ (e.g., surgery for spina bifida) and 4) an infant aged 1 year with GA 280 days, PNA 365 days, PMA 644 days, WT $10 \mathrm{~kg}$ (e.g., orchidopexy).

These simulated results can be used only for preliminary dosing recommendations with close patient monitoring for efficacy and safety since the safety of multiple dosing has not been confirmed in infants and as BSV in pharmacokinetics and-dynamics is significant.

\section{RESULTS}

\section{Patients and Observations}

The characteristics of the study population are shown in Table I. The distribution of PMA, PNA and WT are shown in a supplemental Figure S1. The observed data are shown in Fig. 1, stratified by the study.

\section{Population Pharmacokinetic Model}

A two-compartmental model was applied to describe the timeconcentration data. Clearance was best predicted when it was described as a function of PMA and WT, centered to a median patient of $4 \mathrm{~kg}$ (Eq. 7). The alternative model of exponentially decreasing BDE (Eq. 6) had slightly worse fit to data $(\mathrm{dOFV}=31.8$ with one parameter less). The parameter estimates, their standard errors, and the bootstrap nonparametric confidence intervals for the model with the PMA-based maturation function are presented in Table II. Overall, the parameters were estimated with good precision. Bootstrap results are based on 951 runs with successful minimizations out of 1000. The BSV of clearance was higher in neonates than in older children $(p<0.001)$, when modeled according to Eq. 10.

Body weight adjusted volume of distribution was highest in the smallest infants $(p<0.001)$. The decrease in WT-adjusted central and peripheral volumes of distribution were best described with the allometric power model (Eq. 8).
A good agreement between the observations and model predictions was obtained (Fig. 2). Plots of NPDE versus time and covariates showed no bias (Fig. 3). The typical parameter values in the final model are described graphically in a supplemental Figure S2, and so are the distribution of the random effects (etas) for clearance and volume of distribution (supplemental Figures S3 and S4).

\section{Representative Dosing Simulations}

We simulated a loading dose of $0.1 \mathrm{mg} / \mathrm{kg}$ of oxycodone hydrochloride trihydrate and subsequent maintenance doses for four virtual patients to keep the average oxycodone plasma concentration at $25 \mathrm{ng} / \mathrm{ml}$ (Table III). The goal was to maintain oxycodone plasma concentrations between 10 and $50 \mathrm{ng} / \mathrm{ml}$. The probability for maintaining oxycodone concentration within this range was approximately $90 \%$ with 1 -h dose interval (Fig. 4). The probability was over 70\% with 4 -h dose interval except for the 1-year old infant with the shortest elimination half-life (Fig. 4). The elimination half-life of oxycodone is significantly longer in typical neonates than in older infants because of relatively lower clearance and relatively higher volume of distribution (Table III). This reduces the fluctuation of oxycodone plasma concentration within the dose interval, even though the unexplained BSV of clearance is highest in the neonates.

\section{DISCUSSION}

We have studied the developmental pharmacokinetics of oxycodone starting from extremely preterm neonates up to 7 years old children. Elucidating the developmental pharmacokinetics within the first 6 months of life is particularly important because many of the pharmacokinetic changes typically occur during this period (15-17,21). The majority of our pharmacokinetic data came from the recent study with sparse blood sampling (6). These data were supplemented by two earlier published studies with dense sampling $(5,10)$. Combined, these datasets form a robust basis for a population pharmacokinetic model. Until present, a developmental pharmacokinetic model of oxycodone was available only for children older than 6 months of age (4).

Table I Patient Demographics

\begin{tabular}{llll}
\hline & Study I (6) & Study 2 $(10)$ & Study 3 (5) \\
\hline Subjects/samples (n) & $76 / 397$ & $19 / 200$ & $24 / 184$ \\
Bodyweight (kg) & $4(0.52-14 ; 3.27)$ & $13(8-34 ; 8.13)$ & $3.9(1.8-9.3 ; 1.95)$ \\
Postnatal age (days) & $39.5(0-650 ; 156)$ & $960(240-2580 ; 773)$ & $21(1-298 ; 76)$ \\
Postmenstrual age (days) & $300(170-930 ; 168)$ & $1240(520-2860 ; 773)$ & $299(232-578 ; 83.3)$ \\
\hline
\end{tabular}

Data are number of subjects/samples for the first row, and median (range; standard deviation) for the remaining rows 
Fig. I Oxycodone plasma concentrations in Studies I (a), 2 (b), and 3 (c). The dose was $0.1 \mathrm{mg} / \mathrm{kg}$ oxycodone hydrochloride trihydrate (0.087 mg/kg oxycodone hydrochloride) intravenously except ten of nineteen subjects in Study 2 received the same dose intramuscularly. Original sources: Study I (6), Study 2 ( I 0), and Study 3 (5).

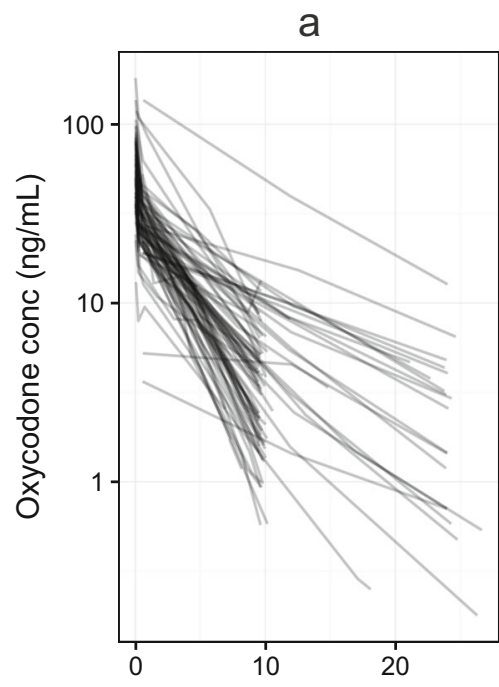

b

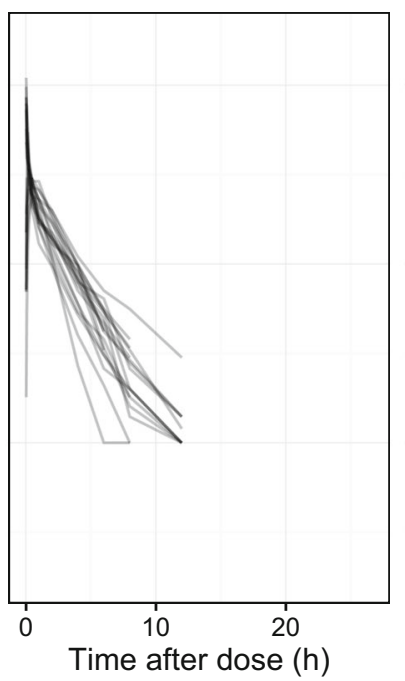

C

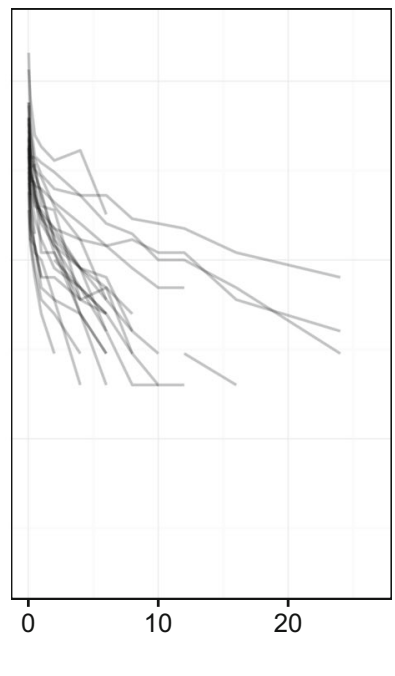

During modeling, we tested two approaches to scale clearance as a function of WT or PMA: BDE model $(15,16,21)$ and the maturation function based on PMA (17). The latter approach described our data slightly better, and the model parameters were estimated with high precision. This is in agreement with previous studies which have shown that the

Table II The Parameter Estimates of the Model

\begin{tabular}{|c|c|c|c|c|c|c|}
\hline & Symbol & Description & Estimate & RSE & $\begin{array}{l}\text { Bootstrap } \\
5 \text { th \% }\end{array}$ & $\begin{array}{l}\text { Bootstrap } \\
95 \text { th \% }\end{array}$ \\
\hline \multirow{7}{*}{$\begin{array}{l}\text { Clearance: } \\
\left.\mathrm{CL}_{\mathrm{i}}=\theta_{1} *(\mathrm{WT} / 4)\right)^{\theta 2 *} \mathrm{PMA}^{\theta 3} /\left(\mathrm{PMA}^{\theta 3}+\theta_{4}{ }^{\theta 3}\right)^{*} \exp \left(\eta_{\mathrm{CL}, i}\right) \\
\text { Where } \eta_{\mathrm{CL}} \text { is distributed with mean of zero, } \\
\quad \text { and standard deviation of } \\
\quad \mathrm{sd}\left(\mathrm{\eta}_{\mathrm{CL}, \mathrm{i}}\right)=\theta_{5}+\theta_{6}{ }^{*} \exp \left(-\mathrm{PNA}{ }^{*} \theta_{7}\right)\end{array}$} & $\theta_{1}$ & Clearance $(L / h)$ for a fully mature $4 \mathrm{~kg}$ infant & 4.60 & $9 \%$ & 4.01 & 5.36 \\
\hline & $\theta_{2}$ & Exponent for clearance scaling by bodyweight & $0.75 \mathrm{FIX}$ & - & - & - \\
\hline & $\theta_{3}$ & Hill coefficient for clearance maturation & 3.82 & $9 \%$ & 3.26 & 4.60 \\
\hline & $\theta_{4}$ & $\begin{array}{l}\text { Postmenstrual age at which clearance is } 50 \% \\
\text { mature (d) }\end{array}$ & 303 & $6 \%$ & 271 & 332 \\
\hline & $\theta_{5}$ & Baseline standard deviation of CL variance & 0.307 & $19 \%$ & 0.00307 & 0.404 \\
\hline & $\theta_{6}$ & Increase in BSV CL at postnatal age of zero & 0.297 & $26 \%$ & 0.198 & 0.604 \\
\hline & $\theta_{7}$ & $\begin{array}{l}\text { Exponent for decrease in clearance variability } \\
(\mathrm{I} / \mathrm{d})\end{array}$ & 0.00440 & $39 \%$ & 0.000465 & 0.00814 \\
\hline \multirow{6}{*}{$\begin{array}{l}\text { Central Vd: } \\
V_{c, i}=\theta_{8} *(W T / 4)^{\theta 10} * \exp \left(\eta_{V c, i}\right) \\
\text { Peripheral } V_{d:} \\
V_{p, i}=\theta_{9} *(W T / 4)^{\theta 10} * \exp \left(\eta_{V p, i}\right)\end{array}$} & $\theta_{8}$ & Central $\mathrm{Vd}(\mathrm{L})$ for an infant of $4 \mathrm{~kg}$ & 5.23 & $6 \%$ & 4.70 & 5.76 \\
\hline & $\theta_{9}$ & Peripheral $\mathrm{Vd}(\mathrm{L})$ for an infant of $4 \mathrm{~kg}$ & 5.91 & $7 \%$ & 5.29 & 6.61 \\
\hline & $\theta_{10}$ & Exponent for $V$ scaling by bodyweights & 0.861 & $10 \%$ & 0.718 & 0.997 \\
\hline & $\theta_{11}$ & Correlation for random effects of $\mathrm{CL}$ and $\mathrm{Vd}$ & 0.743 & $7 \%$ & 0.639 & 0.825 \\
\hline & $\theta_{12}$ & Standard deviation of $\eta_{V c, i}$ & 0.537 & $11 \%$ & 0.433 & 0.644 \\
\hline & $\theta_{13}$ & Standard deviation of $\eta_{\mathrm{vp}, \mathrm{i}}$ & 0.511 & $12 \%$ & 0.398 & 0.608 \\
\hline \multirow{9}{*}{$\begin{array}{l}\text { Inter-compartmental clearance: } \\
\mathrm{Q}_{\mathrm{i}}=\theta_{14} *(\mathrm{WT} / 4) \\
\text { Absorption rate constant of intramuscular injection: } \\
\mathrm{k}_{\mathrm{a}, \mathrm{i}}=\theta_{15} * \exp \left(\eta_{\mathrm{k} a, i}\right) \\
\text { Bioavailability of intramuscular injection: } \\
\theta_{16} \\
\text { Residual error }\end{array}$} & $\theta_{14}$ & $\begin{array}{l}\text { Intercompartmental clearance for an infant } \\
\text { of } 4 \mathrm{~kg}(\mathrm{~L} / \mathrm{h})\end{array}$ & 22.0 & $13 \%$ & 18.1 & 27.6 \\
\hline & $\theta_{15}$ & $\mathrm{k}_{\mathrm{a}}$ for intramuscular injection $(\mathrm{I} / \mathrm{h})$ & 7.56 & $28 \%$ & 4.83 & 12.5 \\
\hline & $\theta_{16}$ & Bioavailability of intramuscular injection & 0.903 & $11 \%$ & 0.768 & 1.16 \\
\hline & $\omega_{\mathrm{ka}}$ & Standard deviation of $\eta_{k a, i}$ & 0.79 & $35 \%$ & 0.0079 & 1.19 \\
\hline & $\sigma_{1}$ & Proportional error, Study 3 (\%) & 16 & $8.6 \%$ & 13 & 18 \\
\hline & $\sigma_{2}$ & Additive error, Study 3 (ng/mL) & 0.29 & $33 \%$ & 0.0029 & 0.44 \\
\hline & $\sigma_{3}$ & Proportional error, Study 2 (\%) & 15 & $8.3 \%$ & 13 & 17 \\
\hline & $\sigma_{4}$ & Additive error, Study 2 (ng/mL) & 0.49 & $10 \%$ & 0.42 & 0.62 \\
\hline & $\sigma_{5}$ & Proportional error, Study I (\%) & 17 & $11 \%$ & 13 & 20 \\
\hline
\end{tabular}

BSV between-subject variability; CL elimination clearance; $k_{a}$ absorption rate constant; PMA postmenstrual age; PNA postnatal age; $Q$ intercompartmental clearance; RSE relative standard error; $V_{c}$ central volume of distribution; $V_{p}$ peripheral volume of distribution; $V d$ volume of distribution; WT weight 
Fig. 2 Observed oxycodone plasma concentrations versus population predicted (a) and individual predicted (b) concentrations. a

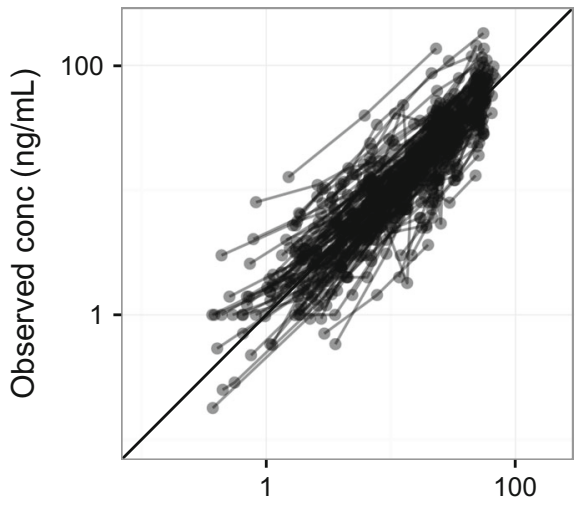

Population predicted conc $(\mathrm{ng} / \mathrm{mL})$ b

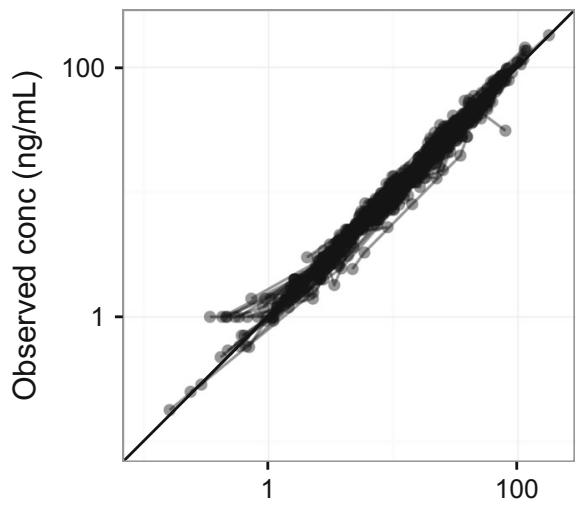

Individual predicted conc $(\mathrm{ng} / \mathrm{mL})$ developmental pharmacokinetics of drugs metabolized by CYP3A enzymes, as is the case also for oxycodone $(6,7)$, can be described with both modeling approaches.

Our data show that the WT-adjusted clearance of oxycodone is lowest in preterm neonates (Table III). On the other hand, the WT-adjusted apparent volume of distribution is highest in this age group. The opposite changes in these WT-adjusted variables with age and WT resulted in marked differences in the elimination half-life with typical values ranging between $8 \mathrm{~h}$ in extremely preterm neonates and $2 \mathrm{~h}$ in infants over 6 months of age.

The maturation of oxycodone clearance within the first months of life seems to be similar to that observed for some other drugs (15-17). Correspondingly, altered volume of distribution in newborns compared to other age groups has also been documented for morphine (22) and paracetamol (acetaminophen) (23). This difference is likely due to the different body composition of the newborns.
Fig. 3 Normalized prediction distribution errors (NPDE) versus time after drug administration (a), body weight (b), postnatal age (PNA) (c) and postmenstrual age $(P M A)(\mathbf{d})$. The model is unbiased if no systematic trends are seen in the distribution errors ( $y$-axis) versus the predictor ( $\mathrm{x}$-axis). Dashed gray line is a local regression smoothing line.
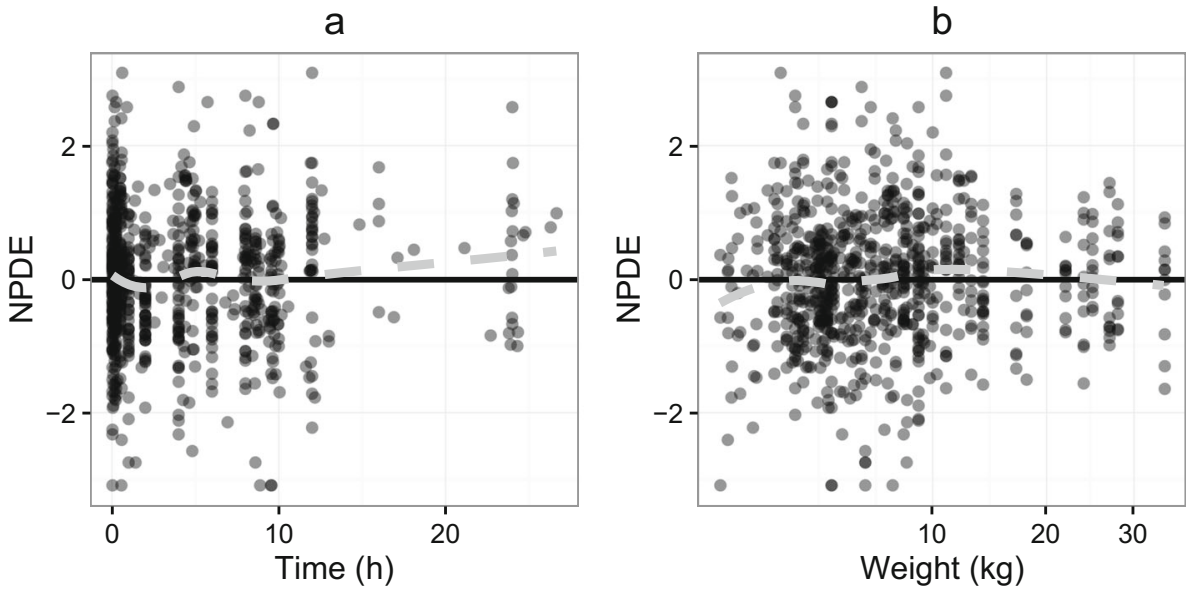

C
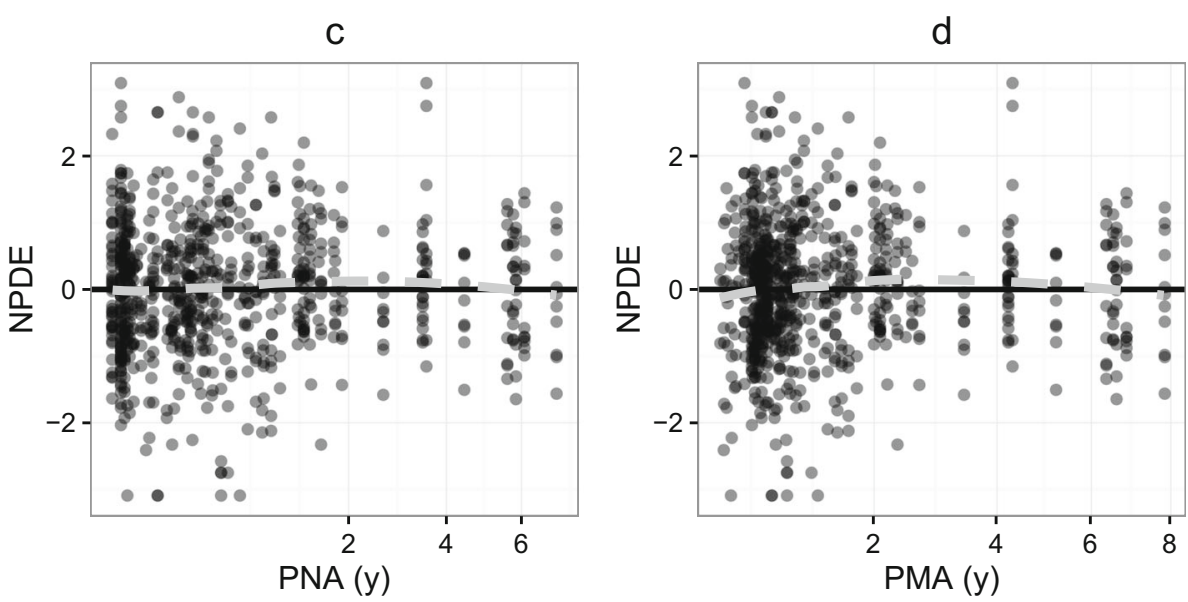
Table III Pharmacokinetic Parameters for the Virtual Patients

\begin{tabular}{llllllll}
\hline Patient & $\begin{array}{l}\text { Postmenstrual } \\
\text { age (days) }\end{array}$ & Weight $(\mathrm{kg})$ & $\mathrm{CL}\left(\mathrm{l} \mathrm{h}^{-1} \mathrm{~kg}^{-1}\right)$ & $\mathrm{V}_{\mathrm{ss}}(\mathrm{l} / \mathrm{kg})$ & $\mathrm{T}_{\mathrm{I} / 2}(\mathrm{~h})$ & $\operatorname{Dose}_{\mathrm{Ih}}(\mu \mathrm{gg} / \mathrm{kg})$ & $\mathrm{Dose}$ 4h $(\mu g / \mathrm{kg})$ \\
\hline Extremely preterm neonate & 187 & 0.5 & 0.26 & 3.7 & 9.9 & 10 & 35 \\
Modest/ate preterm neonate & 246 & 2.2 & 0.42 & 3.0 & 5.2 & 15 & 55 \\
Term neonate & 281 & 3.5 & 0.51 & 2.8 & 4 & 15 & 65 \\
Infant aged I year & 644 & 10.0 & 0.87 & 2.5 & 2.1 & 25 & 110
\end{tabular}

$C L$ elimination clearance; $V_{s s}$ apparent volume of distribution at steady state (the sum of central and peripheral volumes); TI/2 elimination half-life; Dose / $h$ Individualized dose for dosing hourly to keep the average plasma concentration at $25 \mathrm{ng} / \mathrm{ml}$; Dose4h Individualized dose for dosing every fourth hour to keep the average plasma concentration at $25 \mathrm{ng} / \mathrm{ml}$. The doses are reported as oxycodone hydrochloride trihydrate and they are rounded to the nearest value that is divisible by five. The dose can be converted to oxycodone base or oxycodone hydrochloride by multiplying the dose by 0.78 or 0.87 , respectively
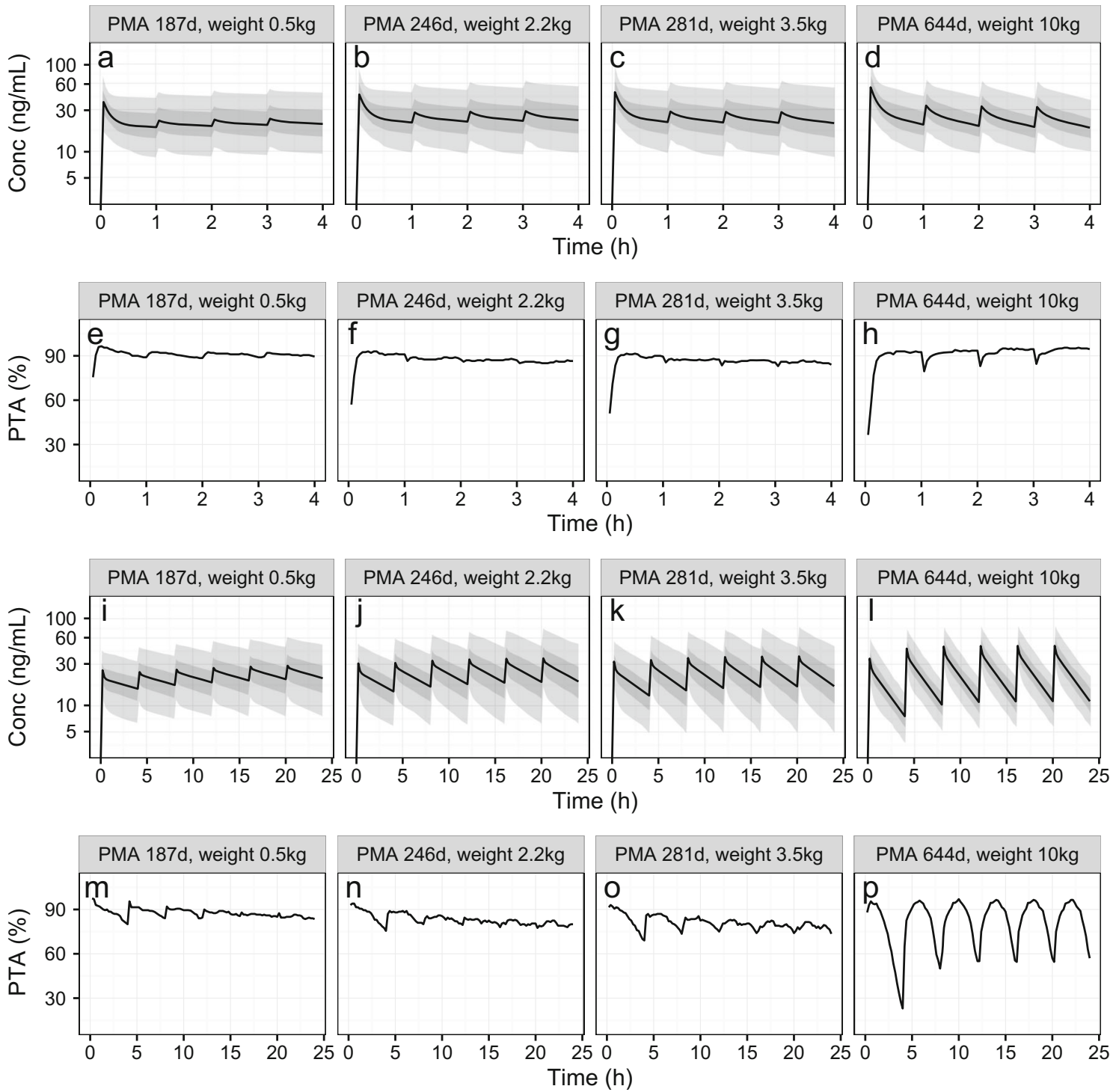

Fig. 4 Simulated oxycodone plasma concentrations for repeated intravenous administration. The loading dose is $0.1 \mathrm{mg} / \mathrm{kg}$ oxycodone hydrochloride trihydrate, and maintenance doses are subsequently administered hourly $(\mathbf{a}-\mathbf{h})$ or at every fourth hour (i-p) to keep the average concentration at $25 \mathrm{ng} / \mathrm{ml}(\mathrm{see}$ Table III). The four panel columns from left to right correspond to the four representative patients; an extremely preterm neonate, a late preterm neonate, a term neonate, and an infant aged I year, respectively. In panels $(\mathbf{a}-\mathbf{d})$ and $(\mathbf{i}-\mathbf{l})$, the black solid lines are population predictions without variability and gray, transparent areas are the 5-95\% percentiles and 25-75\% percentiles of simulated values for 200 virtual patients, respectively. Panels $(\mathbf{e}-\mathbf{h})$ and $(\mathbf{m}-\mathbf{p})$ show the probability of maintaining the target concentration between 10 and $50 \mathrm{ng} / \mathrm{ml}$ for the respective patients. PMA postmenstrual age, PTA probability of target attainment. 
We utilized the model to simulate repeated intravenous oxycodone doses in four clinically relevant scenarios (Fig. 4). These simulations reveal the key features in oxycodone pharmacokinetics in neonates and infants. First, the increased BSV at first days of life can be seen in the youngest virtual patients. Second, the decrease in elimination half-life can be seen with increasing PMA and WT. This decrease in elimination halflife results both from increasing clearance and decreasing relative volume of distribution.

The maintenance doses calculated using typical clearance (Table III) keep oxycodone plasma concentration of virtual patients between 10 and $50 \mathrm{ng} / \mathrm{ml}$ most of the time with $1-\mathrm{h}$ dose interval (Fig. 4). The probability for maintaining the concentration within this range decreases with 4-h dose interval, especially for the 1 -year old infant with the short elimination half-life. The analgesic concentration of oxycodone in infants has not been established. Based on data in 18 healthy children having ophthalmic surgery under halothane anesthesia, a minimum analgesic concentration of $12 \mathrm{ng} / \mathrm{ml}$ was proposed (20). In adults with laparoscopic cholecystectomy a minimum effective concentration of 20-30 $\mathrm{ng} / \mathrm{ml}$ has been presented (19). In case reports of oxycodone intoxication in children plasma oxycodone concentrations have been significantly higher, $600-1360 \mathrm{ng} / \mathrm{ml}(24,25)$. Thus, the oxycodone plasma concentration of $10-50 \mathrm{ng} / \mathrm{ml}$ used in these simulations could be considered appropriate. However, because of the large random BSV in oxycodone pharmacokinetics quantified in the current study and the expected large variability in oxycodone pharmacodynamics, individual dose titration is warranted. These simulation results should be considered as preliminary proposals, and oxycodone, as all opioid analgesics, should be administered with caution before further efficacy and safety data in pediatric patients are available. Furthermore, the safety of repeated oxycodone doses remains to be evaluated in this population.

\section{CONCLUSION}

We have quantified the developmental pharmacokinetics of oxycodone and proposed initial dose recommendation for initial titration of oxycodone analgesia in small children. However, as between-subject variability in pharmacokinetics appears to be pronounced, close follow-up for efficacy and safety is warranted especially in preterm and newborns.

\section{ACKNOWLEDGMENTS AND DISCLOSURES}

This study was funded by a governmental research grant number 507A002 from the Hospital District of Northern Savo, Kuopio, Finland. The authors thank professor
Catherijne A.J. Knibbe for her critical comments during the preparation of the manuscript.

\section{COMPLIANCE WITH ETHICAL STANDARDS}

Conflicts of Interest Pyry Välitalo, Merja Kokki, Veli-Pekka Ranta, Klaus Olkkola, Andrew Hooker and Hannu Kokki have no conflicts of interest that are relevant to this work.

Ethical Approval All procedures were in accordance with the ethical standards of the institutional research committee and with the 1964 Helsinki declaration and its later amendments.

\section{REFERENCES}

1. Kokki H, Laisalmi M, Vanamo K. Interpleural bupivacaine and intravenous oxycodone for pain treatment after thoracotomy in children. J Opioid Manag. 2006;2(5):290-4.

2. Lindell-Osuagwu L, Hakkarainen M, Sepponen K, Vainio K, Naaranlahti T, Kokki H. Prescribing for off-label use and unauthorized medicines in three paediatric wards in Finland, the status before and after the European Union Paediatric Regulation. J Clin Pharm Ther. 2014;39(2):144-53.

3. Axelin A, Kirjavainen J, Salanterä S, Lehtonen L. Effects of pain management on sleep in preterm infants. Eur J Pain. 2010;14(7): 752-8.

4. El-Tahtawy A, Kokki H, Reidenberg BE. Population pharmacokinetics of oxycodone in children 6 months to 7 years old. J Clin Pharmacol. 2006;46(4):433-42.

5. Pokela ML, Anttila E, Seppälä T, Olkkola KT. Marked variation in oxycodone pharmacokinetics in infants. Paediatr Anaesth. 2005;15(7):560-5.

6. Kokki M, Heikkinen M, Välitalo P, Hautajärvi H, Hokkanen J, Pitkänen $\mathrm{H}$, et al. Maturation of oxycodone pharmacokinetics in neonates and infants. I. Oxycodone and its metabolites in plasma and urine. Br J Clin Pharmacol. 2016. doi:10.1111/bcp.13164.

7. Lalovic B, Kharasch E, Hoffer C, Risler L, Liu-Chen LY, Shen DD. Pharmacokinetics and pharmacodynamics of oral oxycodone in healthy human subjects: role of circulating active metabolites. Clin Pharmacol Ther. 2006;79(5):461-79.

8. Lemberg KK, Heiskanen TE, Neuvonen M, Kontinen VK, Neuvonen PJ, Dahl ML, et al. Does co-administration of paroxetine change oxycodone analgesia: an interaction study in chronic pain patients. Scand J Pain. 2010;1(1):24-33.

9. Mikus G, Klimas R. Contribution of oxycodone and its metabolites to the analgesic effect. Br J Anaesth. 2014;1 12(5):944-5.

10. Kokki H, Rasanen I, Reinikainen M, Suhonen P, Vanamo K, Ojanperä I. Pharmacokinetics of oxycodone after intravenous, buccal, intramuscular and gastric administration in children. Clin Pharmacokinet. 2004;43(9):613-22.

11. Beal SL, Sheiner LB, Boeckmann AJ, Bauer RJ. NONMEM user's guides. Ellicott City: Icon Development Solutions; 2013.

12. R Development Core Team: R. A language and environment for statistical computing. Vienna, Austria, 2014, in http://www.Rproject.org. Accessed 3 Nov 2016.

13. Lindbom L, Pihlgren P, Jonsson EN, Jonsson N. PsN-Toolkit-a collection of computer intensive statistical methods for non-linear mixed effect modeling using NONMEM. Comput Methods Prog Biomed. 2005;79(3):241-57. 
14. Beal SL. Ways to fit a PK model with some data below the quantification limit. J Pharmacokinet Pharmacodyn. 2001;28(5):481504.

15. Wang C, Peeters MYM, Allegaert K, van Oud-Alblas HJ B, Krekels EHJ, Tibboel D, et al. A bodyweight-dependent allometric exponent for scaling clearance across the human life-span. Pharm Res. 2012;29(6):1570-81.

16. Bartelink IH, Boelens JJ, Bredius RGM, Egberts ACG, Wang C, Bierings $\mathrm{MB}$, et al. Body weight-dependent pharmacokinetics of busulfan in paediatric haematopoietic stem cell transplantation patients: towards individualized dosing. Clin Pharmacokinet. 2012;51(3):331-45.

17. Anderson BJ, Holford NHG. Mechanism-based concepts of size and maturity in pharmacokinetics. Annu Rev Pharmacol Toxicol. 2008;48:303-32.

18. Nguyen THT, Comets E, Mentré F. Extension of NPDE for evaluation of nonlinear mixed effect models in presence of data below the quantification limit with applications to HIV dynamic model. J Pharmacokinet Pharmacodyn. 2012;39(5):499-518.

19. Kokki M, Broms S, Eskelinen M, Rasanen I, Ojanperä I, Kokki H. Analgesic concentrations of oxycodone - a prospective clinical PK/ PD study in patients with laparoscopic cholecystectomy. Basic Clin Pharmacol Toxicol. 2012;110(5):469-75.
20. Olkkola KT, Hamunen K, Seppälä T, Maunuksela EL. Pharmacokinetics and ventilatory effects of intravenous oxycodone in postoperative children. Br J Clin Pharmacol. 1994;38(1):7 1-6.

21. Wang C, Sadhavisvam S, Krekels EH, Dahan A, Tibboel D, Danhof M, et al. Developmental changes in morphine clearance across the entire paediatric age range are best described by a bodyweight-dependent exponent model. Clin Drug Investig. 2013;33(7):523-34.

22. Bouwmeester NJ, Anderson BJ, Tibboel D, Holford NH. Developmental pharmacokinetics of morphine and its metabolites in neonates, infants and young children. Br J Anaesth. 2004;92(2): 208-17.

23. Anderson BJ, van Lingen RA, Hansen TG, Lin YC, Holford NH. Acetaminophen developmental pharmacokinetics in premature neonates and infants - a pooled population analysis. Anesthesiology. 2002;96(6):1336-45.

24. Levine B, Moore KA, Aronica-Pollak P, Fowler DF. Oxycodone intoxication in an infant: accidental or intentional exposures? J Forensic Sci. 2004;49(6):1358-60.

25. Armstrong EJ, Jenkins AJ, Sebrosky GF, Balraj EK. An unusual fatality in a child due to oxycodone. Am J Forensic Med Pathol. 2004;25(4):338-41. 